\title{
Indirect word priming in connected semantic and phonological contexts
}

\author{
CARMEN OVERSON and GEORGE MANDLER \\ University of California, San Diego, La Jolla, California
}

\begin{abstract}
Indirect activation was explored by presenting subjects with short passages and poems that were designed to activate relevant semantic and phonological (rhyming) representations. The effect of activation was tested with the word completion test in which subjects completed initial stems of target words. The targets were related to the semantic and phonological contexts but had not themselves been presented in the passages. Both semantic and phonological contexts produced equivalent, but short-lasting, activation effects. Evidence is presented that such effects are automatic, without subjects' (conscious) reference to the source of the activation.
\end{abstract}

In the context of continuing work on the dual process model of activation and elaboration (Mandler, 1979, 1980), a previous study by Mandler, Graf, and Kraft (1986) - to be referred to as MGK-explored effects of direct and indirect activation on subsequent word completion performance. In MGK direct activation was explored by presenting target words in the (surrounding) context of either other members of the semantic category to which the target belonged or words that rhymed with the target. Indirect activation was tested by presenting the category members and rhymes but not the target word, and testing the (previously not seen) target word, which was a member of the category or a rhyme. Activation (word priming) was tested by the word completion test in which subjects are given the initial letters of a word and are required to complete this stem with the first word that comes to mind (Warrington \& Weiskrantz, 1970; see also Graf \& Mandler, 1984; Graf, Mandler, \& Haden, 1982). The target word is one of several possible completions for the relevant stem.

In MGK direct activation produced significant facilitation of target stem completions. Indirect activation (where the actual target words were not initially presented) facilitated target completion for rhyming and for semantic contexts, but the rhyming effect was significantly greater than the semantic effect. Both effects dissipated after $10 \mathrm{~min}$.

In MGK, contextual (indirect) activation of the perceptual/phonological component of the rhymes produced greater facilitation in the subsequent completion task than did the conceptual/categorical activation of the category members. In principle, there is no reason why the entire set of members belonging to a particular category should not be activated by appropriate manipulations. The recognition data in MGK indicate that subjects quite clearly encoded the particular categories used, as demonstrated by a high percentage of responses to unpresented but related

The research reported here was supported by National Science Foundation Grant BNS 84-04228. Address requests for reprints to: George Mandler, Center for Human Information Processing, University of California, San Diego, La Jolla, CA 92093. items, the indirect false-alarm rate. In contrast, the completion data showed little activation of these categorically related items.

Because little evidence was found in MGK of specific item activation for the categorical items as a function of having category members presented, in the present experiment we explored the possibility that more effective activation of the category will in fact produce spreading activation to specific nonpresented category members. In MGK subjects were given lists of words with the context generated by the nature of the surrounding words in the list. Creating conditions in which subjects are more likely to consider the category as a whole may produce activation for all category members. Furthermore, the present experiment is intended to explore the kinds of activation that are more likely to occur in natural situations. People are rarely exposed to lists of rhymes or category members, but they do encounter rhyming poems and connected discourse about particular kinds of categories (e.g., about furniture or animals or food). In general, this kind of "natural" activation is more closely related to the everyday experiences of reminding, when information "comes to mind" without any prior search or conscious cue for that information (see Mandler, 1985).

In this experiment subjects were presented with short passages, brief stories or four-line poems. Subjects read several instances of each kind of passage and were then given a stem completion test. This process was repeated with new passages, resulting in Phase 1 and Phase 2 of the experiment. The stems consisted of three letters, some of which could be completed to produce words belonging to one of the conceptual categories, and others to form words that rhymed with the poems that had been presented. None of these target words had been seen during the initial presentation.

\section{METHOD}

\footnotetext{
Subjects

Ninety-six students participated for credit in an introductory psychology course. Twelve subjects were randomly assigned to each of eight groups.
} 


\section{Design}

Four groups served in the experimental conditions, and the other four groups served as controls. The experimental groups read 12 short passages, some of which were poems and some of which were stories. Each passage contained four members of either a rhyming or a semantic category. Following this presentation, all subjects completed a completion test that consisted of target words and distractors. The target words were members of a particular rhyming set or of a category presented in the passages, but the target words themselves had not been presented in the passages. The control subjects did not read any passages, but they completed the same stems as did the experimental subjects. In this way, the data from the control groups provided baseline completion rates to which the experimental completion rates could be compared.

\section{Materials}

Target words. For the rhyming condition, six common rhymes were selected, each having at least 8 rhyming words (Lees, 1981). Four of these words were used in creating the poems. The remaining words constituted a pool from which the target words were drawn. For the semantic condition, six categories were selected from the categories in Battig and Montague (1969). Four of the 10 most frequently generated words in each category were used in the stories, and the other 6 were added to the target pool. All words were eliminated from the target pool if (1) they shared the first three letters with a word from another category (either semantic or rhyming), (2) they rhymed with a word from another category, or (3) they belonged to more than one category. This resulted in a pool of 78 words that were used in a pilot study of baseline completion rates.

Baseline study. In MGK targets were selected on the basis of frequency of occurrence and number of words beginning with the same three-letter stem. In the present experiment pretested words were used because of the large number of targets needed and in order to control for the possibility that word frequency of occurrence is not directly related to probability of completion. For example in the baseline study, TRIal was never completed, but its word frequency is 134 , whereas DIAl had a $40 \%$ completion rate and a word frequency value of only 1 .

Stems formed by the first three letters of each of the 78 words were randomly arranged on a single sheet of paper. Forty-five subjects were instructed to write the first word that came to mind that began with each of the three-letter stems. For each of the $\mathbf{7 8}$ words, the probability of giving the completions that matched the target words was computed. Based on their completion rates, four words were then selected from each of the 12 (6 rhyming and 6 semantic) categories. Because the baseline completion rate in previous studies was about $10 \%$, we attempted to select words so that the average completion rate would be about the same. The percent of completion for the words chosen ranged from $0 \%$ to $44 \%$, with an average of $11.6 \%$. At least 3 other completions had to be given for each three-letter stem in order for it to be selected; an average of 10.60 other completions were given. All targets were 4-12 letters long, with a mean frequency of occurrence per million of 45.29 (Kucera \& Francis, 1967). This procedure resulted in the selection of 24 rhyming targets and 24 semantic targets. Table 1 shows, for each type of category (rhyming and semantic), examples of the 4 words used in the passage, the 4 target words, and alternate completions.

Stimuli. Using 4 of the words from each of the six rhyme categories, six four-line poems were constructed, with the rhymes appearing at the ends of the lines. Six stories were also constructed, each including 4 of the words in a semantic category. The stories were slightly longer than the poems; the mean number of words was 32 for the poems and 41 for the stories. Sample passages are shown below:

\section{There was an old man who sat in a chair Who rocked all day and combed his hair. People would come from miles to stare, And in return the man would glare.}

Lucy was making a spaghetti dinner. Everything was a mess. She spilled oregano all over the floor, and her sauce really had problems. Someone had put cinnamon in the paprika can, and Lucy put it in the sauce. To top it off, she got pepper in her nose and couldn't stop sneezing.
Table 1

Example of Presented Words, Stems, Targets, and Alternate Completions

\begin{tabular}{|c|c|c|c|}
\hline & Presented & Targets & Alternates \\
\hline Rhyming & $\begin{array}{l}\text { CHAIR } \\
\text { HAIR } \\
\text { STARE } \\
\text { GLARE }\end{array}$ & $\begin{array}{l}\text { SCAre } \\
\text { WEAr } \\
\text { BEAr } \\
\text { SHAre }\end{array}$ & $\begin{array}{l}\text { SCAle } \\
\text { WEAve } \\
\text { BEAn } \\
\text { SHApe }\end{array}$ \\
\hline Semantic & $\begin{array}{l}\text { OREGANO } \\
\text { CINNAMON } \\
\text { PAPRIKA } \\
\text { PEPPER }\end{array}$ & $\begin{array}{l}\text { CLOves } \\
\text { GARlic } \\
\text { CURry } \\
\text { SUGar }\end{array}$ & $\begin{array}{l}\text { CLOck } \\
\text { GARden } \\
\text { CURe } \\
\text { SUGgest }\end{array}$ \\
\hline
\end{tabular}

The 12 passages (6 poems and 6 stories) were randomly divided into two groups, A and B, each consisting of 3 poems and 3 stories. Early results indicated that the passages were not adequately distributed between A and B. Therefore, two more groups, C and D, were formed by combining 3 passages (either 2 poems and 1 story or 2 stories and 1 poem) from each of $A$ and $B$. The subjects were exposed to all 12 passages in one of four combinations: $A$ then $B, B$ then $A, C$ then $D$, or $\mathrm{D}$ then $\mathrm{C}$.

Each passage was typed on the upper portion of a single page. To ensure that the subjects read and attended to the passages, they were required to rate each passage according to how interesting or boring they thought it was. They circled a number from 1 to 7 , with 1 being extremely interesting and 7 being extremely boring. The interesting/boring rating scale appeared on the bottom of the same page as the passage. The six passages in each group were presented in six different orders, according to a randomized Latin square. Each set of six passages was followed by a stem completion test. Thus, within each material set (AB, $\mathrm{BA}, \mathrm{CD}$, or DC), there were six different material orders. Two subjects saw each order, resulting in 12 subjects per material set.

Completion test. Four forms of the completion test were used, one for each of the four passage sets (A, B, C, D). Each test consisted of 48 three-letter word stems. Half of the stems could be completed to form the target words for that set. The remaining 24 stems were distractors. The distractors were selected according to the following criteria: (1) they could not be completed with any words that belonged to any of the 12 target categories (rhyming or semantic), and (2) they could be completed with at least 10 words that had a Kucera and Francis (1967) frequency rating of between 10 and 100 . The target and distractor stems were randomly arranged on one sheet of paper.

Recognition test. The recognition test consisted of 2 nonrhyming, noncategorical words from each passage (24 in total) plus 24 distractors of similar type (nouns, verbs, adjectives, and adverbs). The words were randomly arranged on one sheet of paper. The subjects were instructed to circle words they had seen in the passages and cross out the ones they had not seen. The recognition test was used only to preserve the integrity of the experiment until after the debriefing period. Therefore, no data associated with it will be presented.

\section{Procedure}

The subjects were tested in groups of 4 to 12 , with all subjects in a group being in either an experimental or a control group. Each experimental subject was given a material packet containing the six passages from one group (A, B, C, or D) and the corresponding completion test (Phase 1), then the six remaining passages (from another group) and the related completion test (Phase 2). The subjects were told to quickly read each passage, and then to rate it. The subjects were told that the completion task was a time filler, and that the last completion task would be followed by a memory test. Because we hypothesized that the subjects' knowing the nature of the time filler (the completion test) might somehow affect their processing of the passages, the task was not described until after the first six passages had been read. Obviously, the subjects were familiar with the completion test during the second half of the experiment. This difference allowed for the testing of any effect of such familiarity with the completion test, by comparing the completion rates from Phases 1 and 2. 
The subjects were given $20 \mathrm{sec}$ in which to read each passage and rate it. They were asked to turn the page (passages were separated by blank, colored sheets) and wait until told to begin reading the next one. In this way the subjects worked at their own paces, but the time from exposure to a passage until the completion test was approximately the same for all subjects. Most subjects took 8-15 sec to read and rate each passage. They were allowed as much time as necessary on the completion tests and on the recognition test, although no subject required more than $3 \mathrm{~min}$ on any test; in other words, stems were completed on the average in less than $4 \mathrm{sec}$. The time course from the first passage until the beginning of the completion test was approximately $3 \mathrm{~min}$ for Phase 1 and $2 \mathrm{~min}$ for Phase 2, with the difference being due to the instructions for the first completion test.

On the completion test, the subjects were instructed to write down the first English word that came to mind and that began with those three letters and was not a proper noun. They were told that if they could not think of anything, they could skip it and try again later. Because of the group administration, strict monitoring was not possible and a few (less than $3 \%$ ) omissions and proper nouns occurred.

After all subjects had finished the last completion test, the recognition test was distributed. Following that test, the subjects responded to several questions designed to elicit their interpretations of the experiment. Specifically, we were interested to know to what extent the subjects caught on to the real nature of the experiment (i.e., that some of the stems could be completed with words that were related to words in the passages) and at what point during the experiment this realization occurred.

The 48 control subjects received no passages and only the completion tests. As with the experimental subjects, 12 subjects received each test order: A then B, B then A, C then D, and D then C. The instructions to the controls were the same as those given to the experimental groups for the completion test. In addition, they were told that they were giving normative data for other research.

The basic design, then, included four independent variables. Condition (experimental or control) and type of materials (AB, BA, CD, or DC) were between-subjects variables. Poems versus stories and first versus second phase were within-subjects variables. Separate analyses were performed on the data from the experimental group, which included serial position (distance of a passage from completion test) as a within-subjects variable.

\section{RESULTS AND DISCUSSION}

There was an overall significant effect of prior activation of target items. The mean percent of completions of the target items in the experimental condition was $12.37 \%$, and in the baseline condition it was $9.55 \%$; the mean scores were 1.48 and 1.14 , respectively $[F(1,88)=8.51$, $M S e=1.33] .{ }^{1}$ However, the difference between the two kinds of materials was far from significant: the mean percent of completions for stories was $12.15 \%$ and for poems it was $12.59 \%$; mean scores were 1.29 and $1.33[F(1,88)$ $=0.11, M S e=1.33]$. Nor was there a significant effect due to the two phases of the experiment; the mean percentages for Phases 1 and 2 were $12.24 \%$ and $12.50 \%$, respectively. And finally the $F$ value for the four sets of materials was less than unity. There was a significant triple interaction of condition $\times$ phase $\times$ material set. Apart from the difficulty of interpreting any unanticipated higher order interaction, the means that contribute to this interaction show that Set $\mathrm{A}$ in Phase 1 and Set $\mathrm{C}$ in Phase 2 gave unusually low target completion rates. Since these findings are counter to the basic activation hypothesis and the main effect of condition was still significant, we shall not dwell on this anomalous result.
An examination of the questionnaire results showed that only 9 of the 48 subjects (19\%) gave any indication of having been aware that the words they gave on the completion test were either conceptually or phonologically related to the passages they had read. The mean target completion rate for these subjects was $13.20 \%$; for the other $81 \%$ of the subjects, it was $12.18 \%$. A weighted means solution analysis of variance showed that this difference is not statistically significant $[F(1,40)=0.277$, $p>.50]$.

The data and conclusions are simple and straightforward. Indirect activation produced by connected discourse produces significant effects in the completion task, and these effects are apparently automatic (i.e., they occur without conscious intervention or awareness by the subjects that their productions are a result of the prior exposure). We argue that there was no conscious search for the "appropriate" completions in part because of previous findings that subjects who could not recall any items do well on the completion test, and in part because of the fast average response times in the completion test. As a further test of the effect of conscious knowledge, we ran two additional groups of 12 subjects each on a subset of the poems and stories. The first group was run in the identical way as subjects in the main experiment, but the second group was asked to give as completions words that were related to words they had seen in the poems and stories (i.e., related either by meaning or rhyme). The mean percent of completing stems with the target words was $19.1 \%$ for the second group and $9.7 \%$ for the first; the mean scores were 2.29 and $1.67[F(1,16)=16.86, M S e$ $=1.80]$. No other factors were statistically significant. The number of stem completions left blank (i.e., omissions) also showed a large effect of instructing subjects to complete stems with words related to the presentation items. In all other experiments and conditions the percentage of omissions was $1 \%$ or less, whereas under this condition it was $11.5 \%$. In addition, the average response time on the completion test was approximately seven times greater for the "informed" group. Thus, deliberate search for appropriate completions improves performance to twice that when subjects give the first word that comes to mind, subjects tend to omit a large number of items if they cannot find an appropriate completion, and they take much longer to do the task. The absence of omissions and the fast responses also argues that in the main experiment subjects did not act deliberately with the presentation task in mind when doing the completion task.

In contrast to MGK, where indirect activation produced significantly greater facilitation for the rhyming than for the categorical context, we found that the rhyming condition and the categorical condition produce an equivalent amount of indirect activation of phonologically and conceptually related items. We found that there was in fact spreading activation to the individual nonpresented but related members of the semantic category. In the present experiment individual items of the relevant categories are given as completions to relevant word 
stems. It is reasonable to conclude that connected discourse (i.e., brief stories) produced greater activation of the underlying category than did the mere presentation of category members in MGK.

As far as the time course of the decay of the indirect activation in this experiment is concerned, we noted earlier that the completion tests were given approximately 2-3 min after the six passages had been read, and that the completion test took approximately 2-3 min. Since the target words were spread throughout the test, even the most recent passage did not, on average, have its targets completed until about $1.5 \mathrm{~min}$ later, whereas for the earliest passages the delay was about $3.5 \mathrm{~min}$ on the average.

We explored the nature of indirect activation with the stem completion test. We have shown that indirect activation of phonological components is easily achieved. Such activation can be produced with short rhyming poems or with presentation of other instances of the rhyme (as in MGK). For conceptually related members of a category, mere presentation of other members of the category (as in MGK) does not produce indirect activation. However, given adequate general activation of the conceptual category in the context of connected discourse, activation will spread to other members of the category and produce indirect activation effects in the stem completion test.

\section{REFERENCES}

Battig, W. F., \& Montague, W. E. (1969). Category norms for verbal items in 56 categories: A replication and extension of the Con- necticut category norms. Journal of Experimental Psychology Monograph, 80(3, Pt. 2).

Graf, P., \& MANDler, G. (1984). Activation makes words more accessible, but not necessarily more retrievable. Journal of Verbal Learning \& Verbal Behavior, 23, 553-568.

Graf, P., Mandler, G., \& Haden, P. (1982). Simulating amnesic symptoms in normal subjects. Science, 218, 1243-1244.

KUČERA, H., \& FRANCIS, W. (1967). Computational analysis of presentday American English. Providence, RI: Brown University Press.

LEES, G. (1981). The modern rhyming dictionary. Greenwich, CT: Cherry Lane.

MANDLER, G. (1979). Organization and repetition: Organizational principles with special reference to rote learning. In L.-G. Nilsson (Ed.), Perspectives on memory research. Hillsdale, NJ: Erlbaum.

MANDLER, G. (1980). Recognizing; The judgment of previous occurrence. Psychological Review, 87, 252-271.

Mandler, G. (1985). Cognitive psychology: An essay in cognitive science. Hillsdale, NJ: Erlbaum.

Mandler, G., Graf, P., \& Kraft, D. (1986). Activation and elaboration effects in recognition and word priming. The Quarterly Journal of Experimental Psychology, 38A, 645-662.

Warrington, E. K., \& Weiskrantz, L. (1970). Amnesia: Consolidation or retrieval? Nature, 228, 628-630.

\section{NOTE}

1. We report our result in terms of percent correct completion. However, the analyses were performed on raw scores, which will also be listed together with the statistical information.

(Manuscript received for publication January 12, 1987.) 